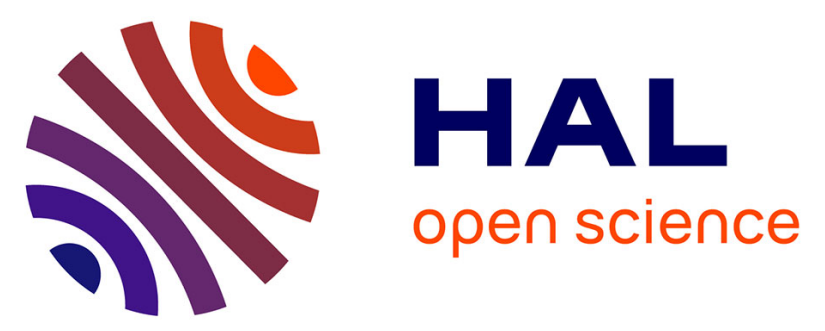

\title{
Performance Measures at the Accident and Emergency Department in Denmark: The Issue of Unified Targets
}

Vivi T. Nguyen, Iskra Dukovska-Popovska, Kenn Steger-Jensen, Hans Henrik Hvolby, Kjeld A. Damgaard

\section{- To cite this version:}

Vivi T. Nguyen, Iskra Dukovska-Popovska, Kenn Steger-Jensen, Hans Henrik Hvolby, Kjeld A. Damgaard. Performance Measures at the Accident and Emergency Department in Denmark: The Issue of Unified Targets. IFIP International Conference on Advances in Production Management Systems (APMS), Sep 2015, Tokyo, Japan. pp.637-645, 10.1007/978-3-319-22759-7_73 . hal-01431154

\author{
HAL Id: hal-01431154 \\ https://hal.inria.fr/hal-01431154
}

Submitted on 10 Jan 2017

HAL is a multi-disciplinary open access archive for the deposit and dissemination of scientific research documents, whether they are published or not. The documents may come from teaching and research institutions in France or abroad, or from public or private research centers.
L'archive ouverte pluridisciplinaire HAL, est destinée au dépôt et à la diffusion de documents scientifiques de niveau recherche, publiés ou non, émanant des établissements d'enseignement et de recherche français ou étrangers, des laboratoires publics ou privés. 


\title{
Performance Measures at the Accident and Emergency Department in Denmark: the issue of unified targets
}

\author{
Vivi T. Nguyen ${ }^{1}$, Iskra Dukovska-Popovska ${ }^{1}$, Kenn Steger-Jensen ${ }^{1}$, \\ Hans Henrik Hvolby ${ }^{1}$, and Kjeld A. Damgaard ${ }^{2}$ \\ ${ }^{1}$ Department of Mechanical and Manufacturing Engineering, Aalborg University, Denmark \\ \{vivi, iskra, kenn, hhh\}@m-tech.aau.dk \\ ${ }^{2}$ Accident and Emergency Department, Sygehus Vendsyssel Hjørring, Denmark \\ kadern.dk
}

\begin{abstract}
The use of performance measures and how they effect in practice for accident and emergency department has been studied in a Danish hospital case. The main findings are that having unified performance targets has consequences for the actual flow of various incoming patients, organization structure, and workflow. Moreover, this study suggests that measuring process lead time and length of stay differentiated by sites and various patient flows will provide a clearer overview of the actual operational performance.
\end{abstract}

Keywords: Performance measures, Performance target, Emergency department, Case study, and Danish health care system.

\section{Introduction and background}

Health care systems worldwide face the challenges in improving clinical quality, enhancing service levels, and expanding the access while at the same time being pressed to reduce costs [1]. In line with this, the Accident and Emergency departments (A\&E) in Denmark have been merged into fewer larger units in order to formalize the organization structure and for patients with multiple diseases to be able to meet with the necessary health professional competencies and specialized equipment as early as possible [2]. Because of these public reforms, and that the A\&E is the entering point of incoming patients when arriving to hospital for acute care, there is a growing attention from the public, politicians, regions and hospitals to measure and improve the A\&E. More specifically, the National Board of Heath has set three performance measures and the Regions, responsible for hospital sector, have set respective targets. Two out of three performance measures are focusing on the waiting times in the initial phases of the diagnostic treatment while the last performance measure is related to the service of informing the patient about length of waiting time [3]. It is important to investigate the effect of setting the measures and targets towards the overall A\&E goal of becoming more patient oriented and efficient.

When setting metrics, it should be linked to how the operation delivers value to its targeted customers [4]. Welch et al. (2011) [5] define such time intervals and show

adfa, p. 1, 2011.

(C) Springer-Verlag Berlin Heidelberg 2011 
more ideal ones covering the main processes as well as subcycle processes and intervals respectively. Sørup et al. (2013) [2] conclude from their study that A\&E time intervals such were the most recommended performance measures followed by patient centeredness and safety performance measures.

A stream in the literature addresses how the performance measures are used in A\&E practice, what results they stimulate and under which conditions, and the challenges they entail $[6,7,8,9]$. Most of these studies are evaluating specific countrybased A\&E performance measures, taking a longitudinal perspective over several years, and considering several hospitals. For example, a number of papers focus on investigating the effects of setting a 4-hour target for length of stay in emergency departments by the English National Health service. Kelman and Friedman (2009)[6], focusing on the 4-hour rule, investigate two types of hypothesized dysfunctional consequences when setting targets (effort substitution and gaming). Their findings showed insufficient evidence of those dysfunctional effects. On the contrary, they identify dramatic wait-time performance improvements. Continuing the studies on the English NHS 4-hour rule, Mason et al. (2012) [7] focused on investigating the time distribution of patients within the target, and found out that establishing a target reduced the proportion of patients staying longer than 4 hours, there were increasing number of patients departing within the last 20 minutes of the target interval, notably, the elderly. In addition, Weber et al. (2011) [8] identify organizational aspects (such as hospital-wide support and ownership) and the lack of that may have negative effects on staff, risks to patients, and may explain why targets fail to be achieved. Investigating in the Australian A\&E target, inspired by the English 4-hour rule, Jones and Schimanski (2010) [10] find that the impact of the introduction of an A\&E time target and the associated massive investments have not resulted in a consistent improvement across the hospitals.

To summarize, the existing literature on A\&E performance measures is country specific and focusing more on the impacts of the targets on the overall A\&E performance. Studies focusing on the Danish A\&E performance measures are scarce. Jensen et al. (2007) [11] investigate the effect of optimized patient reception procedure for patients with broken hip. Therefore, there is a need to investigate the effects of the targets set by the Danish Regions for the operational performance of the A\&Es. The purpose of this paper is to study the use of performance measures and address the challenges performance measures entail in practice based on a case study of a Danish A\&E in Region North Jutland.

\section{Research design}

This research is explorative and applying case study as the methodological approach. In the Danish context, this case, A\&E in Region North Jutland, represents an extreme case because it was one of the first in Denmark to start implementing the reforms and it featured one of the most advanced implementation and improvements [12]. Since, the context and the experiences in the case are critical, applying in-depth case study will enable us to study the issue in its edge, and allow us to gain rich and valid insights knowledge [13]. 
For this study, data regarding understanding the actual flow of patients was gathered through semi-structured interviews with nurses and doctors as well as observations of the various patient flows. The main analysis was based on documents and data sets derived from A\&E hospital event-log system during the period of August 2014 to Marts 2015. Data has been gathered consisting of 17,470 unique entities (patients) from three datasets including patient arrival and departure timestamp, patient activity timestamps, and triage and specialty categorization data, respectively. The data has been cleaned in order to remove cases that were not recorded in all three datasets, cases treated at other departments than A\&E, as well as cases with empty fields (we could differentiate between cases where we can see that a timestamp has not been recorded and cases with empty fields, probably as a result of system error. The second ones were removed from the data set). We ended with a data set of 16,229 unique entities. The data was analyzed inductively in order to investigate different issues related to timestamps affecting the performance measurement of the targets set. The analyses were focusing on the following issues:

- Quality of data registration - Analyzing the frequency of different timestamps registered such as "arrival", "triage begins", "triage ends" etc. This analysis was also done by separating the accident and emergency patients in order to see the differences in these two sites.

- Order of timestamps - The intention of this investigation is to see if the timestamps registered are reflecting the actual or designed patient flow. The analysis included identifying the most frequent ordering of the timestamps registered.

- Fulfilment of performance measures - the dataset including "arrival", "triage begins", "nurse begins", and "doctor begins" has been composed in order to evaluate to what extent the performance targets are fulfilled. In the data set, 4,039 unique entities have the necessary timestamps mentioned above for this analysis. In addition, the performance fulfillment was identified at the accident and at the emergency unit respectively. A Mann-Whitney U test (non-parametric statistic test) was used to identify if there are significant differences in the performances at the two sites.

- Process lead time - a Mann-Whitney U test (non-parametric statistic test) has been used in order to compare the significant differences of process lead time of triage, nurse and doctor including length of stay for the accident and emergency units respectively. Significant results were considered those with a p value of less than .05 for all analyses.

For the analyses, a hybrid model has been used to identify and remove outliers. Data points are identified as outliers, if they are larger or smaller than $q 3 \pm w(q 3-q 1)$, where $\mathrm{w}=1.5$. Q1 and $\mathrm{q} 3$ are the 25 th and 75 th percentiles, respectively.

\section{Case description}

The A\&E North is a part of a Region North Jutland in Denmark, which has set the following three performance measures and their targets for all region's A\&Es [14]: 
1. The start of triage has to be within 15 minutes from the arrival. The target is reached in $95 \%$ of the cases.

2. The diagnosing and treatment has to be initiated within an hour from arrival. The target is $85 \%$ of the cases.

3. The patient has to be informed about the expected waiting time. The target is $90 \%$ of the cases.

This second performance measure has been also defined as "all the patients should be seen by an appropriate health professional within an hour", where doctors and nurses are defined as health professional [3]. In this case, the nurses are primarily the first contact that patients meet with health professionals. Thus, this study uses the timestamp "arrival" and" nurse begins" for the second performance measure.

In order to accommodate the variety of incoming patients the A\&E North is divided into two sites each with own team of doctors and nurses but is managed by the same executive consultant (chief of doctor): accident site and emergency site. The emergency site is treating patients with medical related ill-condition and with high potential to be admitted. The accident site is treating patients with orthopedic injuries and with less complex symptoms of illness. The patient at the arrival will be met by the visitation nurse informing him/her about the expected waiting time. Based on given information, the visitation nurse refers to the site, which is most suitable for treating the patient based on the character of illness and symptoms. Following this, a triage nurse will examine the patient based on the triage procedure in order to categorize the patient into a triage code and a medical specialty. Patients with extremely critical health conditions are treated separately in trauma rooms by specialists from different specialties. After triage, the triage nurse, in most of the cases, also the responsible for the care of the patient during the stay at A\&E. Bloodtests are conducted on all patients at emergency site. Patients, who need a radiology imaging such as X-ray to determine a diagnosis will need to be transferred to radiology imaging service units. When a doctor is available, he sees the patient. The A\&E North has a bed ward facility of 32 beds for further observation of patients if needed. The total length of stay at the A\&E is maximum 48 hours, after which other departments in the hospital need to take the patient into care.

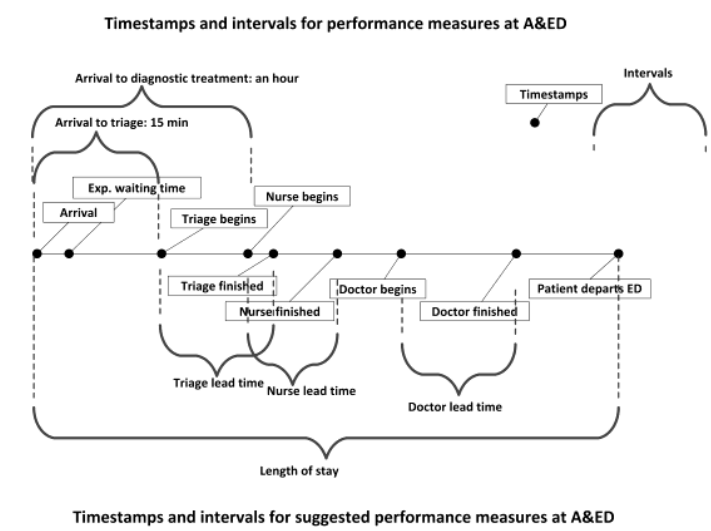


Fig. 1. Timeline of ED timestamps and time intervals for performance measures

A\&E North has an event-log system where different timestamps of activities are registered and it provides an overview of all current patients flow and status. In addition, it provides data for monitoring and analysis of the different performance measures. The staff has to register a timestamp from the work-station at the start and end of seeing a patient. Figure 1 presents the different timestamps and time intervals as they typically occur in A\&E for each patient. The timestamps and time intervals above the timeline are for monitoring the three performance measures, whereas those beneath the timeline present the performance targets and other time intervals relevant for the analysis.

\section{$4 \quad$ Analysis}

\subsection{Lack of registration \& order of timestamps}

The analysis highlighted an inconsistency in timestamp registration in the event-log system. In general, timestamps of finishing an activity occur more frequently than timestamps connected to start of an activity. Absence of commencing timestamps for the triage activity are the most extreme case; the "triage ends" is the second most frequently used timestamp in the system with $88 \%$ while the "triage begins" timestamp is registered in only $31 \%$ of these cases.

The timestamps necessary for evaluating the second and third performance targets have been registered for $78 \%$ and $88 \%$ of all patients, respectively. In total timestamps for all three performance measures were available for only $25 \%$ of all patients. Looking at the accident site and emergency site separately, the frequency of registering timestamps for monitoring the three performance measures is different. The emergency site has higher registration frequency for "triage begins", "nurse begins", and "informing patients about expected waiting time", which are $41 \%, 84$ $\%$, and $95 \%$, respectively. For accident site, the registration frequencies are $13 \%, 66$ $\%$, and $75 \%$, respectively.

Investigating the order of the timestamps indicates that some timestamps are registered right after each other (within 1 minute time period). The timestamps for "informing about expected time" and "triage begins" are in $84 \%$ of the time registered within the same minute. The "nurse begins" is in $82 \%$ of the cases registered at the same time as "triage begins", whereas they finish in $67 \%$ of the cases at the same time. Looking at the flow of accident site and emergency site separately, the tendencies of timestamp order are corresponding to the overall view of A\&E.

\subsection{Fulfillment of performance target}

Looking at the timestamp data, A\&E North fulfills two performance targets out of three. The second performance target - first contact with health professional staff to be within an hour from arrival, is achieved in $92 \%$ of the cases. The third performance target - the patients should be informed of the expected waiting time, is achieved in 
$93 \%$ of the cases. However, the first performance measure is not fulfilled as the target of $95 \%$ of the cases is within 56 minutes. Hence, $69 \%$ of the cases are within 15 minutes. Figure 2 shows the boxplots for the first and second performance measures and targets.
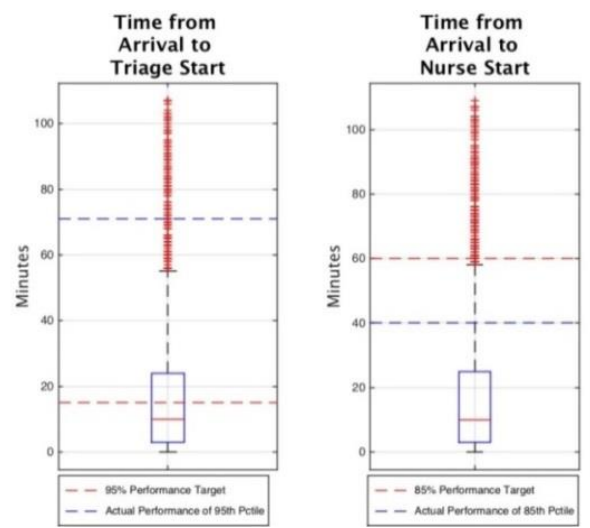

Fig. 2. Boxplots of the time interval from arrival to triage begins and to first contact with health professional begins, respectively.

\subsection{Comparing performance measures at the accident and the emergency sites} Looking at the time intervals reflecting the performance measures, Table 1, where it can be observed that based on Mann-Whitney test each of them is significantly different between the accident and emergency site. In addition, both times at the accident site are greater than the times at the emergency site. $A S$ and $E S$ are abbreviation for accident site and emergency site, respectively.

Table 1. Time intervals reflecting performance measures

\begin{tabular}{|c|c|c|c|c|c|c|c|}
\hline & & $\mathrm{n}$ & Mean \pm SD & Median & IQR & Z & Sig \\
\hline \multirow{2}{*}{$\begin{array}{l}\text { Arrival - } \\
\text { triage begins }\end{array}$} & AS & 324 & $25.7 \pm 21.2$ & 19 & $8-40$ & \multirow{2}{*}{-11.5} & \multirow{2}{*}{$\mathrm{p}<0.001$} \\
\hline & ES & 3496 & $13.7 \pm 16.6$ & 7 & $3-18$ & & \\
\hline \multirow{2}{*}{$\begin{array}{c}\text { Arrival - } \\
\text { nurse begins }\end{array}$} & AS & 325 & $32.5 \pm 28.0$ & 24 & $9.8-50$ & \multirow{2}{*}{-11.8} & \multirow{2}{*}{$\mathrm{p}<0.001$} \\
\hline & ES & 3510 & $16.4 \pm 20.9$ & 8 & $3-21$ & & \\
\hline
\end{tabular}

Table 2 summarizes the results of the Mann-Whitney tests conducted to compare separately the process lead times of triage, nurse, and doctor, as well as length of stay between accident site and emergency sites. The triage and nurse process times are significantly longer at the accident site. On the contrary, the doctor time and the length of stay at A\&E are significantly longer at the emergency site.

Table 2. Time intervals for triage, nurse and doctor processes, and time of stay

\begin{tabular}{cccccccc}
\hline & & $\mathrm{n}$ & Mean \pm SD & Median & IQR & Z & Sig \\
\hline Triage begins- & AS & 662 & $51.0 \pm 45.7$ & 38.5 & $13-81$ & -7.3 & $\mathrm{p}<0.001$ \\
triage ends & ES & 3871 & $33.4 \pm 30.6$ & 24 & $14-42$ & & \\
\hline Nurse begins- & AS & 3681 & $74.4 \pm 62.7$ & 56 & $26-108$ & -21.6 & $\mathrm{p}<0.001$ \\
nurse ends & ES & 7834 & $51.6 \pm 53.0$ & 31 & $17-65$ & & \\
\hline
\end{tabular}




\begin{tabular}{cccccccc}
\hline $\begin{array}{c}\text { Doctor begins- } \\
\text { doctor ends }\end{array}$ & AS & 3866 & $52.0 \pm 59.1$ & 29 & $14-69$ & 44.7 & $\mathrm{p}<0.001$ \\
\hline \multirow{2}{*}{ Arrival-departs } & AS & 5841 & $124.7 \pm 80.5$ & 109 & $63-166$ & 37.0 & $\mathrm{p}<0.001$ \\
& ES & 5278 & $188.3 \pm 98.9$ & 171 & $116-244$ & & \\
\hline
\end{tabular}

\section{$5 \quad$ Discussion and Conclusion}

This section discusses the challenges that happen in practice when setting joint targets as well as performance measure that focus only on part of a patient flow. One of the challenges relates to inconsistent registration of the timestamps. This inconsistency is especially large at the triage process, and when looking at the accident site. It is important to investigate what are the causes of these differences in registration as well as their effect on the statistical significance of the conclusions.

The setup of performance measures and the targets does not take into account the actual process setup. In the case, the performance measures "arrival to triage begins" and "arrival to the first contact with health professional staff" indicate that there are two different processes to be measured. However, looking at the actual patient flow, the triage and the initial contact at A\&E North are provided by the same nurse, which will be responsible for the care of this particular patient during the stay at A\&E. Looking at the order of timestamps, it appears that in $84 \%$ of the cases, the timestamps for triage begins and nurse begins are registered at the same point of time. This may indicate that the process of triage and start of treatment are overlapping. In the case that they do not overlap, and could be seen as separate processes, it may indicate that the nurse might not be the same providing the triage. From A\&E perspective, these performance measures do not contribute to getting an insight of how well they perform as they measure the same activity. From a Region perspective, they do not provide a reliable overview of the actual performance. The "arrival to first contact with a health professional staff" measure has a longer target (1 hour) but it actually measures same as the other performance measure which has a target of 15 minutes. It can be questioned whether the intention of the modified performance target is to show a better target result rather than providing relevant information about the performance minutes. Thus, there is a need for a clear guideline of the data collection methods and the purpose of each performance target.

The findings regarding the length of time intervals corresponding to the performance measures in Table 1 suggest that performance targets should be differentiated between accident site and emergency site. Looking at the lead times for triage and nurse processes in Table 2 we could see that the process times of these activities may affect the waiting times prior to those processes. For example, the process time of triage at accident site being longer than the process time of triage at emergency site (Table 2) may indicate why the patients at accident site wait longer for triage start than the patients at emergency site (Table 1). Thus, it is suggested to also measure process lead time of triage, nurse and doctor as well as the total length of stay. In addition, the targets of performance measure should be differentiated between the two sites. This will provide valuable insight from A\&E perspective of the performance and create a foundation for examining possible trigger for any changes in perfor- 
mance systematically. Another challenge in the registration of timestamps is that some activities are not covered in the registrations such as bloodtests, radiology imaging diagnostic etc. These registrations of the treatment process are important in the patient flow, even though they are not provided by the A\&E staff, as these affect the performance of the department.

Looking at a health care quality in total, performance measures of how fast A\&E can provide a treatment is not enough. The quality of service and treatment need to be considered when evaluating the performance and improvement. Thus, it is necessary that the further studies focus on how to design a performance measurement system that balances different performance measures and create the right environment and behavior that will help the A\&E to fulfill performance target. These studies need to take into consideration the context and the organization structure.

\section{References}

1. Brailsford, S., Vissers, J.: OR in healthcare: A European perspective. Eur. J. Oper. Res. 212, 223-234 (2011).

2. Sørup, C., Jacobsen, P., Forberg, J.: Evaluation of emergency department performance - a systematic review on recommended performance and quality-in-care measures. Scand. J. Trauma Resusc. Emerg. Med. 21, 62 (2013).

3. Region Nordjylland: Region Nord forretningsudvalget: 10. Servicemål på akutområdet 2. kvartal 2014, https://dokumenter.rn.dk/edocpublishing/edocPunkt.aspx?id=987\&punktguid=01027028-7105-41e7-8d04-f3c879660a21, (2014).

4. Melnyk, S.A., Stewart, D.M., Swink, M.: Metrics and performance measurement in operations management: dealing with the metrics maze. J. Oper. Manag. 22, 209-218 (2004).

5. Welch, S.J., Asplin, B.R., Stone-Griffith, S., Davidson, S.J., Augustine, J., Schuur, J.: Emergency Department Operational Metrics, Measures and Definitions: Results of the Second Performance Measures and Benchmarking Summit. Ann. Emerg. Med. 58, 33-40 (2011).

6. Kelman, S., Friedman, J.N.: Performance improvement and performance dysfunction: an empirical examination of distortionary impacts of the emergency room wait-time target in the English National Health Service. J. Public Adm. Res. Theory. mun028 (2009).

7. Mason, S., Weber, E.J., Coster, J., Freeman, J., Locker, T.: Time Patients Spend in the Emergency Department: England's 4-Hour Rule-A Case of Hitting the Target but Missing the Point? Ann. Emerg. Med. 59, 341-349 (2012).

8. Weber, E.J., Mason, S., Carter, A., Hew, R.L.: Emptying the Corridors of Shame: Organizational Lessons From England's 4-Hour Emergency Throughput Target. Ann. Emerg. Med. 57, 79-88.e1 (2011).

9. Pines, J.M., Hilton, J.A., Weber, E.J., Alkemade, A.J., Al Shabanah, H., Anderson, P.D., Bernhard, M., Bertini, A., Gries, A., Ferrandiz, S., Kumar, V.A., Harjola, V.-P., Hogan, B., Madsen, B., Mason, S., Öhlén, G., Rainer, T., Rathlev, N., Revue, E., Richardson, D., Sattarian, M., Schull, M.J.: International Perspectives on Emergency Department Crowding. Acad. Emerg. Med. 18, 1358-1370 (2011).

10. Jones, P., Schimanski, K.: The four hour target to reduce emergency department "waiting time": A systematic review of clinical outcomes: The UK four hour rule. Emerg. Med. Australas. 22, 391-398 (2010).

11. Jensen, P.S., Holm, M., Christiansen, F.T., Foss, N.B., Kehlet, H.: Optimeret modtagelsesprocedure for hoftefrakturpatienter. Ugeskr La Eger. 169, 808 (2007).

12. Sikkert Patientflow - English, http://sikkertpatientflow.dk/english/.

13. Yin, R.K.: Case study research: Design and methods. sage (2009).

14. Region Nordjylland: Servicemål for sygehuse, http://www.rn.dk/Sundhed/Til-sundhedsfaglige-ogsamarbejdspartnere/Servicemaal-og-HSMR-tal/Servicemaal-for-sygehuse. 